\title{
Johan Wahyudi. Penentuan Titik Lokasi Baru Pelayanan Kesehatan Bagi Penyandang 2020 Disabilitas Di Kota Banjarmasin Menggunakan Metode Ahp dan Gis \\ PENENTUAN TITIK LOKASI BARU PELAYANAN KESEHATAN BAGI PENYANDANG DISABILITAS DI KOTA BANJARMASIN MENGGUNAKAN METODE AHP DAN GIS
}

\author{
Johan Wahyudi \\ Program Studi Teknik Informatika, STMIK Indonesia Banjarmasin \\ Jalan Pangeran Hidayatullah Banua Anyar, Banjarmasin Kalimantan Selatan \\ Email : johan77@stmik.id
}

\begin{abstract}
ABSTRAK
Konsep Smart City yang diasung oleh pemerintah Kota Banjarmasin bertujuan agar memudahkan masyarakatnya untuk merasakan layanan serta fasilitasnya dalam melakukan pengembangan kemajuan pengetahuan dan teknologi untuk melayani kepentingan publik. Namun, beberapa layanan serta fasiltas umum yang salah satunya adalah pelayanan kesehatan masyarakat (puskesmas) sebagian besar masih belum ramah untuk para penyandang disabilitas. Dalam implemantasinya digunakanlah sistem informasi geografis sebagai wadah informasi persebaran puskesmas secara spasial, serta metode AHP (Analytical Hierarchy Process) untuk melakukan pengambilan keputusan dalam menentukan lokasi mana yang membutuhkan pembangunan fasilitas yang ramah dan menunjang para penyandang disabilitas secara efektif dengan menyederhanakan dan memperepat proses pengambilan keputusan dengan memecahkan persoalan tersebut dalam suatu susunan hirarki.

Hasilnya adalah sebuah sistem informasi geografis yang dapat memudahkan penggunanya untuk menentukan dan memutuskan lokasi atau pelayanan kesehatan masyarakat mana yang membutuhkan pembangunan pelayanan disabilitas agar ramah dan menunjang bagi para penyandang disabilitas.
\end{abstract}

Kata Kunci : Disabilitas, Analytical Hierarchy Process, pelayanan kesehatan

\section{ABSTRACT}

The concept of Smart City which is promoted by the government of Banjarmasin City aims to make it easier for its people to experience the services and facilities in developing knowledge and technology advances to serve the public interest. However, some public services and facilities, one of which is the public health service (puskesmas), are largely not friendly to persons with disabilities. In its implementation, a geographic information system is used as an information container for the spatial distribution of health centers, as well as the AHP (Analytical Hierarchy Process) method to make decisions in determining effective locations requiring the construction of friendly facilities and supporting persons with disabilities by simplifying and accelerating the decision-making process to solve problems. in a hierarchical arrangement.

The result is a geographic information system that can make it easier for users to determine and decide which locations or public health services require the development of disability services to be friendly and supportive for persons with disabilities.

Keywords: Disability, Analytical Hierarchy Process, health service

\section{PENDAHULUAN}

Kota Banjarmasin adalah salah satu ibukota yang bisa dibilang merupakandaerah cukup maju hampir seperti kota metropolitan pada umumnya. Konsep SmartCity yang diasung oleh pemerintah kota bertujuan agar memudahkan masyarakatnyauntuk merasakan layanan serta fasilitasnya dan juga menunjukan bagaimanapemerintah kota secara serius untuk melakukan pengembangan kemajuan pengetahuandan teknologi untuk melayani kepentingan publik. Layanan serta fasilitas umum yangdiberikan pemerintah kepada warganya adalah hak-hak yang pantas diterima, sudahsewajarnya semua layanan dan fasilitas umum bebas dipakai oleh siapa saja.

Banyak dari layanan sertafasilitas umum di Kota Banjarmasin yang masih belum ramah untuk para penyandang disabilitas. Salah satu cara untuk menentukan titik atau lokasi mana yang belumtersedia pelayanan serta fasilitas ramah bagi penyandang disabilitas adalah denganmenyajikan informasi secara geografis. Sistem informasi geografis merupakan sebuah sistem informasi yangmenyajikan data berupa data spasial beserta data-data pendukung lainnya. Sistem 


\section{Jurnal Sains Komputer dan Teknologi Informasi $\mid$ Page e - issn: 2655-7460. Volume 3 No.1, November 202060 - 69}

inidapat sangat berguna bagi instansi, lembaga dan pemerintahan untuk melakukanperencanaan pembangunan hingga pemeliharaan aset atau layanan serta fasilitasumum, khususnya yang ramah untuk penyandang disabilitas.

Rumusan masalah yang akan dibahas adalah bagaimanamengimplementasikan sistem informasi geografis dan Metode AHP untuk penentuan titik lokasi barusesuai dengan penyusunan kriteria-kriteria dalam penentuan lokasi pelayanandisabilitas baru menjadi sebuah aplikasi yang sesuai untuk mempermudah danmembantu serta merekomendasikan untuk penentuan titik lokasi baru pelayanandisabilitas di Kota Banjarmasin. Tujuan dari penelitian ini adalah untuk penentuan titik lokasi baru pelayanan bagi penyandang disabilitas di Kota Banjarmasin agar dapat diterapkan dan dimanfaatkan bagi Pemerintah Kota Banjarmasin. Metode AHP (Analytical Hierarchy Process) digunakan sebagai dasar teori untuk analisis dan penilaian penentuan titik lokasi pelayanan disabilitas baru. Sistem ini akan menampilkan informasi-informasi yang terkait dengan sistem informasi geografis (GIS) dari pusat kesehatan masyarakat (Puskesmas) di Kota Banjarmasin dan penilaian untuk menentukan pembangunan pelayanan baru bagi penyandang disablitas di setiap Puskesmas.

\section{TINJAUAN PUSTAKA}

\subsection{Disabilitas}

Pada tahun 2006, Perserikatan Bangsa-Bangsa (PBB) telah mengesahkan Konvensi Hak- Hak Penyandang Disabilitas (UNCRPD) yang hingga saat ini telah diratifikasi oleh 164 negara, termasuk Indonesia. Menurut UNCRPD, disabilitas merupakan hasil interaksi antara keterbatasan fungsi individu (mobilitas, penglihatan, pendengaran, dan komunikasi) dengan kondisi lingkungan sekitar yang menghambat partisipasi aktif dan efektif dalam masyarakat. Artinya, individu yang memiliki keterbatasan fungsi (impairment) akan menjadi disabilitas ketika berhadapan dengan hambatan lingkungan (disabled), seperti fasilitas yang tidak aksesibel, tidak tersedianya alat bantu atau persepsi negatif masyarakat.Dengan kata lain, disabilitas tidak sama dengan diagnosa medis yang menjelaskan kondisi keterbatasan fungsi, tetapi lebih menjelaskan bagaimana individu dapat berfungsi dalam lingkungannya.

Berdasar dari angka yang ditetapkan oleh WHO (World Health Organization) terdapat 15\% Penyandang
Disabilitas di Indonesia. Dengandemikian terdapat populasi mencapai 36.841, 956 dengan populasi keseluruhan penduduk 245 juta (WHO, 2012). Dari banyaknya para penyadang disabiltas maka diperlukanlah aksesibilitas atau kemudahan agar mobilitas mereka dalam beraktifitas dapat berjalan beriringan agar menciptakan lingkungan inklusi atau lingkungan yang nyaman untuk berbaur tanpa memandang keterbatasan.

Disabilitas terdiri atas disabilitas fisik, disabilitas sensorik, disabilitas mental dan disabilitas intelektual. Berikut penjelasannya :

a. Disablitas Fisik dan Disabilitas Sensorik

Disabilitas fisik didefinisikan sebagai adalah terganggunya fungsi gerak, antara lain amputasi, lumpuh layuh atau kaku, paraplegi, celebral palsy (CP), akibat stroke, akibat kusta, dan orang kecil sedangkan disabilitas sensorik atau diklasifikasikan sebagai disabilitas aural dan visual berarti terganggunya salah satu fungsi dari panca indera, antara lain disabilitas netra, disabilitas rungu, dan/atau disabilitas wicara.

b. Disablitas Mental dan Disabilitas Intelektual Disabilitas mental didefinisikan sebagai terganggunya fungsi pikir, emosi, dan perilaku, antara lain: a) psikososial di antaranya skizofrenia, bipolar, depresi, anxietas, dan gangguan kepribadian; dan b) disabilitas perkembangan yang berpengaruh pada kemampuan interaksi sosial di antaranya autis dan hiperaktif. Sedangkan disabilitas intelektual didefinisikan sebagai terganggunya fungsi pikir karena tingkat kecerdasan di bawah rata-rata, antara lain lambat belajar, disabilitas grahita dan down syndrom.

Di Kota Banjarmasin tercatat 3.897 penyandang disabilitas yang tinggal di Banjarmasin, yang mewakili $0.56 \%$ dari total populasi. Dari lima kecamatan di kota ini, Banjarmasin Barat (1052) dan Banjarmasin Selatan (1190) adalah rumah bagi lebih dari setengah jumlah total penyandang disabilitas di Banjarmasin, sementara sisanya tinggal di kecamatan sekitarnya, yaitu Banjarmasin Tengah (490), Banjarmasin Timur (579), dan Banjarmasin Utara (586).

\subsection{AHP (Analytical Hierarchy Process)}

Analytical Hierarchy Process (AHP) adalah suatu teori atau metode ungguldalam pengambilan keputusan multikriteria dengan beberapa faktor yang dikeloladalam struktur hierarki (Saaty, 1990). Hierarki dalam AHP dimaksudkan pada urutansecara menurun tingkatan level 


\section{Johan Wahyudi. Penentuan Titik Lokasi Baru Pelayanan Kesehatan Bagi Penyandang Disabilitas Dí Kota Banjarmasin Menggunakan Metode Ahp dan Gis}

mulai dari tujuan suatu kriteria yang bersangkutan,subkriteria, dan alternatif-alternatif pada urutan level-level selanjutnya.Metode ini adalah sebuah kerangka untuk mengambil keputusan dengan efektifatas persoalan yang sangat kompleks dengan menyederhanakan dan mempercepatproses pengambilan keputusan dengan memecahkan persoalan kedalam bagianbagiannya,menata dalam suatu susunan hirarki, memberi nilai numerik padapertimbangan subjektif tentang pentingnya setiap variabel dan menetapkan variableyang mana yang memiliki prioritas paling tinggi dan bertindak untuk mempengaruhi

hasil pada situasi tersebut. Terdapat tiga prinsip utama dalam pemecahan masalahdalam AHP menurut Saaty, yaitu: Decomposition, Comparative Judgement, danLogical Concistency.

Prinsip-prinsip penyelesaian masalah AHP secara garis besarmeliputi tahapan berikut:

\section{Decomposition (Menyusun Hierarki)}

Persoalan yang telah terdefinisi dipecah menjadi unsur-unsur, sehinggadiperoleh beberapa tingkatan. Proses inilah yang disebut hierarchy (hirarki),yang dibuatberdasarkan keuntungan dan kerugian yang diperoleh jikakitamengambil keputusan tersebut.

2.Comparative Judgement (Perbandingan Tingkat Kepentingan)

Membuat kepentingan relatif antara dua elemen, pada suatu tingkat tertentu,terkait dengan elemen pada tingkat sebelumnya. Penilaian ini adalah inti AHP.Hasil penilaian ditempatkan dalam bentuk matriks yang lazim disebut pairwisecomparison. Penilaian terhadap elemen meliputi:

a. Elemen mana yang lebih(penting/disukai/berpengaruh dan lainnya).

b. Berapa kali sering (penting/disukai/berpengaruhdan lainnya) Saatmengunakan skala kepentingan sebagai patokan agar diperoleh skala yangbermanfaat ketika membandingkan dua elemen.

3. Synthesis of Priority (Perbandingan Tingkat Kepentingan)

Mencari nilai eigen vector untuk setiap matriksperbandingan berpasanganuntuk mendapatkan local priority. Karena matriks-matriks perbandinganberpasangan ada pada setiap level, maka untuk mendapatkan prioritas globalperlu dilakukan sistesis antara local priority. Pengurutan elemen- elemenmenurut kepentingan relatif melelui prosedur sintesis disebut prioritysynthesis.

\section{Logical consistency}

Konsistensi dua makna, yaitu:

a. Objek-objek yang serupa dapat dikelompokkan sesuaidengankeseragaman dan relevansi.

b. Menyangkut tingkat hubungan objek - objek berdasarkan kriteria tertentu.

\subsection{Langkah-langkah AHP}

Menurut Permadi (1992), metode AHP mempunyai kemampuan untuk memecahkan maslah yang multi objektif dan multi kriteria yang berdasar pada perbandingan preferensi dari setiap elemen dalam hierarki. Prosedur atau langkah-langkah penyelesaian masalah dalam AHP yaitu:

1) Mendefinisikan masalah, menetapkan tujuan, melakukan pengembangan alternatif jika AHP digunakan untuk penyusunan prioritas alternatif.

2) Menyusun masalah dalam bentuk hierarki, terdiri dari tujuan, kriteria dan alternatif.

3) Menyusun prioritas untuk tiap elemen masalah pada tiap tingkat hirarki. Diawali dengan menyusun perbandingan berpasangan dalam bentuk matriks, sehingga disebut matriks perbandingan berpasangan (pairwise comparison).

4) Menghitung bobot prioritas dengan langkah sebagai berikut:

a. Jumlahkan nilai pada satu kolom ke kolom ke-j dan lakukan pada setiap kolom. Persamaann ditunjukan sebagai berikut:

$$
\sum_{i=1}^{n} x_{i j}, \quad \mathrm{j}=1,2,3, \ldots, n
$$

Dengan $X \mathrm{ij}$ adalah suatu matriks pada baris ke- $I$ dan kolom ke-j.

b. Bagilah setiap nilai dalam satu kolom ke-j dengan nilai jumlah kolom tersebut, sehingga nilai jumlah kolom yang baru sama dengan satu. Persamaan dapat ditunjukan sebagai berikut:

$$
\sum_{i=1}^{n} \frac{x_{i j}}{\sum_{i=1}^{n} x_{i j}}, \quad \mathrm{j}=1,2,3, \ldots, n
$$

Dengan $X \mathrm{ij}$ adalah nilai pada baris $\mathrm{ke}-i$ dan kolom ke-j.

c. Jumlahkan nilai pada baris ke- $I$ kemudian bagi dengan bbanyaknya kriteria. Persamaan dapat ditunjukan sebagai berikut: 


\section{Jurnal Sains Komputer dan Teknologi Informasi Page e - issn : 2655-7460. Volume 3 No.1, November 202060 - 69}

$$
\begin{aligned}
& \sum_{j=1}^{n} x_{i j}, \quad \mathrm{i}=1,2,3, \ldots, n \\
& W_{i}=\frac{1}{n} \sum_{j=1}^{n} x_{i j}, \quad \mathrm{j}=1,2,3, \ldots, n
\end{aligned}
$$

Dengan Xij adalah nilai pada baris ke-i dan kolom ke-j, $\mathrm{n}$ adalah jumlah kriteria dan Wi adalah bobot prioritas ke- $i$.

5). Menghitung bobot alternatif.

a. Jumlahkan nilai pada satu kolom ke-j dan lakukan pada setiap kolom. Persamaan ditunjukan sebagai berikut:

$$
\sum_{i=1}^{n} a_{i j}, \quad \mathrm{j}=1,2,3, \ldots, n
$$

Dengan aij adalah suatu matriks pada baris ke-I dan kolom ke-j.

b. Bagilah setiap nilai dalam satu kolomdengan nilai jumlah kolom tersebut, sehingga nilai jumlah kolom yang baru sama dengan satu. Persamaan dapat ditunjukan sebagai berikut:

$$
\sum_{i=1}^{n} \frac{a_{i j}}{\sum_{i=1}^{n} a_{i j}}, \quad \mathrm{j}=1,2,3, \ldots, n
$$

Dengan $a_{\mathrm{ij}}$ adalah nilai pada baris ke- $i$ dan kolom ke-j.

6). Menghitung overall composite weight $(\mathrm{CW})$ atau prioritas global. $\mathrm{CW}$ didapatkan dengan mengalikan bobot prioritas alternative degan bobot prioritas kriteria seperti pada persamaan berikut:

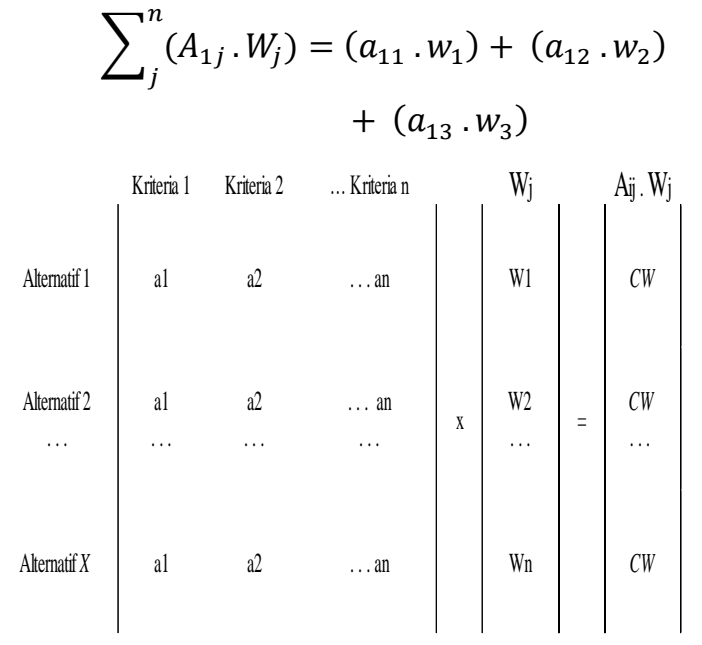

Perkalian bobot prioritas alternatif dengan bobot prioritas kriteria, dimana aij adalah bobot prioritas alternatif ke ke-i pada kriteria ke-j, $\mathrm{Wj}$ adalah bobot prioritas ke-j dan $\mathrm{CW}$ adalah composite weight pada alternatif ke-i. Dari CW didapatkan rekomendasi utama adalah nilai yang terbesar, rekomendasi kedua adalah nilai terbesar kedua dan seterusya hingga rekomendasi terakhir dengan nilai terkecil.

1. Mengukur konsistensi

Melakukan pengujian rasio konsistensi (concictency ratio). Pengujian ini dilakukan untuk menguji kekonsistenan perbandingan antara kriteria yang dilakukan untuk seluruh hierarki.

a. Langkah 1 , menghitung nilai lamda $(\lambda)$ dengan cara :

$\lambda_{i}=\frac{\sum_{j=1}^{n}\left(x_{i j} \cdot W_{j}\right)}{W_{i}}, \mathrm{i}=1,2,3, \ldots, n$

Dimana:

$\lambda_{i}=$ eigen value pada kriteria ke-i.

$\mathrm{Wi}=$ adalah bobot prioritas ke-i.

$\mathrm{Wj}=$ adalah bobot prioritas ke-j.

$x_{i j}=$ adalah nilai pada matriks

perbandingan.

b. Langkah 2, Hitung lamda maksimal $\left(\lambda_{\text {maks }}\right)$ dengan mencari rata-rata dari nilai lamda. Persamaan $\lambda_{\text {maks }}$ ditunjukan sebagai berikut:

$\lambda_{\text {maks }}=\frac{\lambda_{1}+\lambda_{2}+\lambda_{3}+\cdots+\lambda_{n}}{n}$

Dengan $\lambda$ maks adalah rata-rata eigen value dan $\mathrm{n}$ adalah jumlah kriteria.

c. Langkah 2, menghitung indeks konsistensi (CI) dengan cara :

$\mathrm{CI}=\frac{\lambda_{\text {maks }}-\mathrm{n}}{\mathrm{n}-1}$

Dimana :

$\mathrm{CI}=$ indeks konsistensi

$\lambda_{\text {maks }}=$ eign value

$\mathrm{n}=$ banyak elemen.

d. Langkah 3, menghitung rasio konsistensi (CR) dengan cara :

$\mathrm{CR}=\frac{\mathrm{CI}}{\mathrm{RI}_{n}}$

1) RI (Random Indeks) adalah indeks random yang telah ditentukan berdasarkan table RI dan disesuaikan dengan ordo matriks $n$. 


\section{Johan Wahyudi. Penentuan Titik Lokasi Baru Pelayanan Kesehatan Bagi Penyandang Disabilitas Di Kota Banjarmasin Menggunakan Metode Ahp dan Gis}

2) Suatu matriks perbandingan disebut konsisten jika nilai rasio konsistensi $\leq 0,1$ dan hasil perhitungan data dapat dibenarkan.

Tabel 2.1Random Indeks Berdasarkan Ordo Matriks

\begin{tabular}{|l|l|}
\hline Ordo Matriks & RI \\
\hline 1 & 0 \\
\hline 2 & 0 \\
\hline 3 & 0.58 \\
\hline 4 & 0.9 \\
\hline 5 & 1.12 \\
\hline 6 & 1.24 \\
\hline 7 & 1.32 \\
\hline 8 & 1.41 \\
\hline 9 & 1.45 \\
\hline 10 & 1.49 \\
\hline 11 & 1.51 \\
\hline 12 & 1.48 \\
\hline 13 & 1.56 \\
\hline 14 & 1.57 \\
\hline 15 & 1.59 \\
\hline
\end{tabular}

Sumber : Saaty (1990)

\subsection{GeografisInformation System (GIS)}

Sistem informasi geografis (SIG) adalah sebuah sistem infomasi yang biasanya digunakan untuk menyimpan, memanipulasi dan menganalisa informasi secara geografis. Pengertian ini selaras seperti apa yang disampaikan oleh Purwadhi (2001), SIG adalah sebuah sistem yang meorganisir perangkat keras (hardware), perangkat lunak (software) dan data, serta dapat mendayagunakan sistem penyimpanan, pengolahan, maupun analisis data secara simultan, sehingga dapat diperoleh informasi berkaitan dengan aspek keruangan.

SIG adalah sistem basis data dengan kemampuan kemampuan khusus untuk data yang tereferensi secara spasial atau koordinat geografis berikut sekumpulan operasi-operasi yang mengelola data tersebut. SIG dibutuhkan karena untuk data spasial penanganannya sangat sulit terutama karena peta dan data statistik cepat kadaluarsa hingga tidak ada pelayanan penyediaan data dan informasi yang diberikan menjadi tidak akurat.

Pengembangan SIG berbagai macam bentuknya mulai dari aplikasi desktop sampai dengan aplikasi berbasis Website atau yang dikenal dengan WebGIS. WebGIS adalah sebuah aplikasi informasi geografis yang bisa diakses secara online melalui internet/website.

\section{METODE PENELITIAN}

\subsection{Pengumpulan Data}

Pengumpulan data yaitu mengumpulkan data-data yang berhubungan dengan keperluan dalam topik penelitian yang berasal dari buku serta jurnal penelitian sebelumnya, data spasial berupa koordinat latitude dan longtitude dari lokasi tempat instansi pemerintahan dan pelayanan publik dan data non-spasial yang berupa data tentang para penyandang disabilitas yang ada di kota Banjarmasin.

\subsection{Observasi}

Dalam penelitian ini data didapatkan dengan cara observasi, pengumpulan data spasial dan non spasial dilakukan di Dinas Pekerjaan Umum dan Penataan Ruang serta di Dinas Sosial Kota Banjarmasin.

\subsection{Sistem Yang Diusulkan}

Analisa sistem yang dikembangkan adalah kegiatan untuk melihat sistem yang sudah berjalan, melihat bagian mana yang bagus dan tidak bagus, kemudian mendokumentasikan kebutuhan yang akan dipenuhi dalam sistem yang baru. Gambaran fungsionalitas dari sistem aplikasidan deskripsi proses jalannya dan kegunaan sistem aplikasi yang akan kembangkan., dapat dilihat dari use case diagram berikut ini :

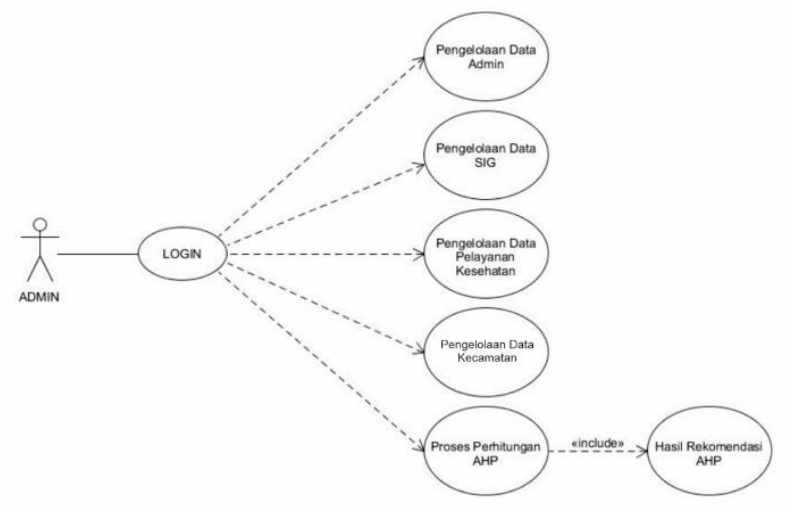

Gambar 3.1 Use Case Diagram

Sedangkan Activity Diagram dari sistem yang diusulkan adalah : 


\section{Jurnal Sains Komputer dan Teknologi Informasi $\mid$ Page e - issn: 2655 7460. Volume 3 No.1, November $202060 \sim 69$}

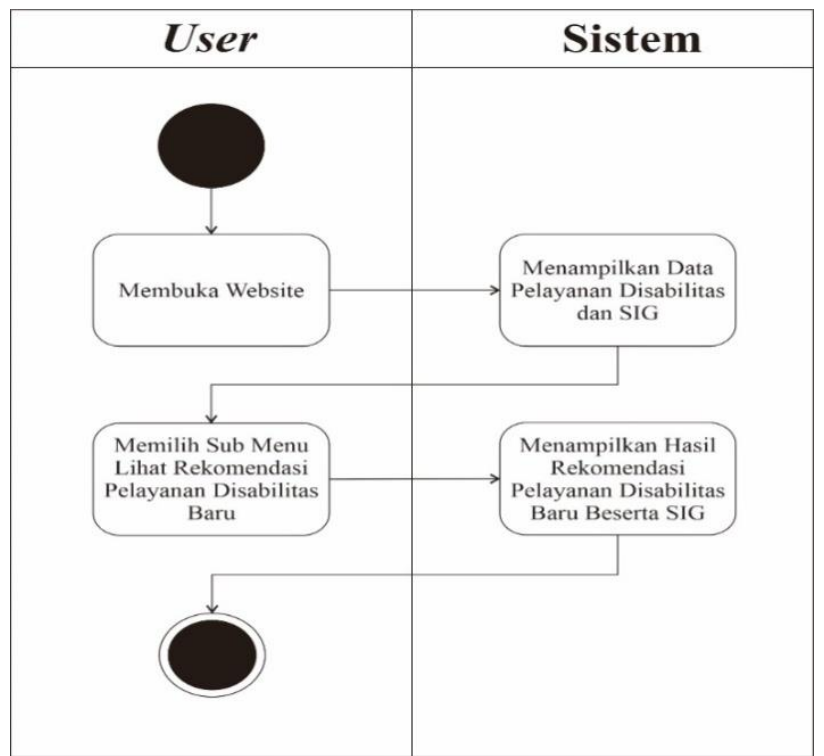

Gambar 3.2 Activity Diagram

Untuk Sequence Diagram dari sistem yang diusulkan sebagai berikut :

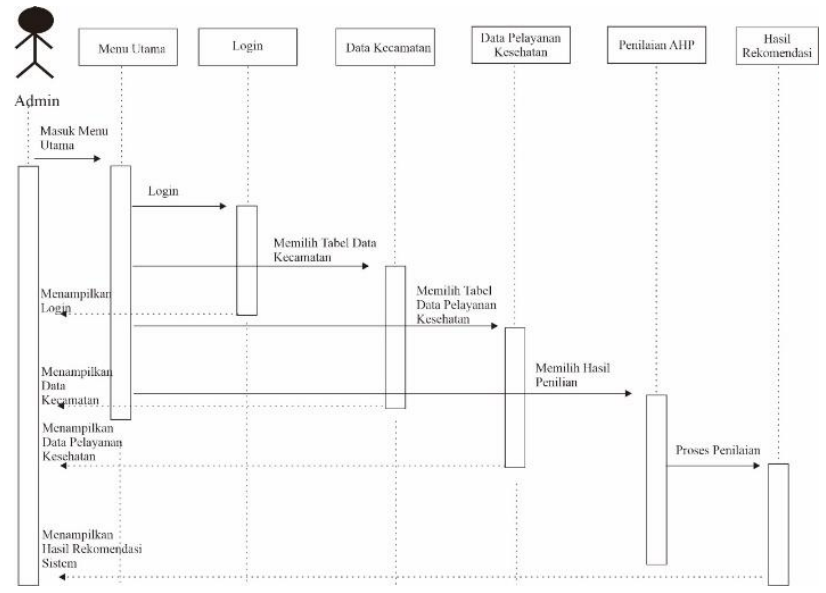

Gambar 3.3 Sequence Diagram

\subsection{Proses Perhitungan AHP}

Dalam sistem informasi geografis untuk penentuan titik lokasi baru pelayanan disabilitas di Kota Banjarmasin ini memiliki kemampuan untuk membantu user menentukan dimana saja titik rekomendasi prioritas pembangunan pelayanan disabilitas di Pusat Pelayanan Maskyarakat (PUSKESMAS) menggunakan metode Analytical HIeraechy Prosess (AHP).Adapun langkahlangkah perhitungan metode AHP yang digunakan dalam sistem adalah sebagai berikut:

1. Membuat Struktur Hirarki Proses
Struktur Hierarki terdiri goal (tujuan utama yang diinginkan) atau dalam penelitian ini goal nya adalah penentuan titik lokasi baru pelayanan disabilitas lalu, kriteria yang didalamnya ada subkriteria dalam mecapai goal dan kriteria alternatifsebagai hasil rekomendasi keputusan dari goal.

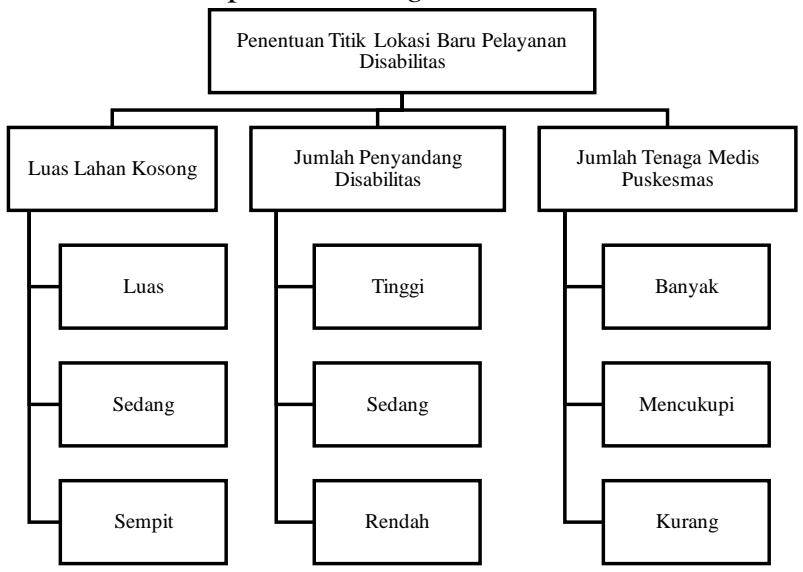

Gambar 3.4 Struktur Hierarki AHP

(Goal dan Kriteria)

Dan kriteria alternatifnya adalah :

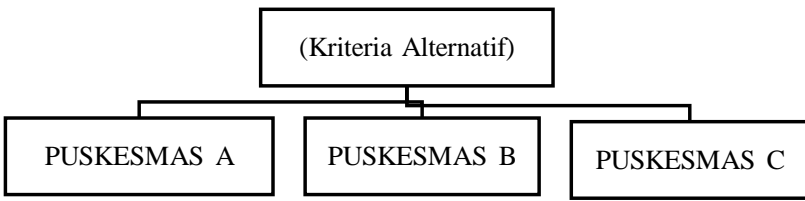

Gambar 3.5 Struktur Hierarki AHP

(Kriteria Alternatif)

\section{HASIL DAN PEMBAHASAN}

Hasil dan pembahasan dari sistem penentuan titik lokasi baru layanan kesehatan bagi penyandang disabilitas melalui beberapa kegiatan. Ada pun kegiatan nya adalah sebagai berikut :

1. Membuat Matriks Perbandingan Berpasangan Kriteria. Matriks perbandingan berpasangan disini merupakan matriks dari nilai perbandingan antara kriteria satu dengan kriteria lainnya sesuai dengan pemberian skala prioritas diatas yang digunakan dalam penentuan nilai untuk penentuan titik lokasi baru pelayanan disabilitas.

Tabel 4.1 Matriks Perbandingan Kriteria 


\section{Disabilitas Di Kota Banjarmasin Menggunakan Metode Ahp dan Gis}

\begin{tabular}{|c|c|c|c|}
\hline & Luas Lahan Kosong & $\begin{array}{c}\text { Jumlah Penyandang } \\
\text { Disabilitas }\end{array}$ & $\begin{array}{c}\text { Jumlah Tenaga } \\
\text { Medis Puskesmas } \\
\text { (Perawat) }\end{array}$ \\
\hline Luas Lahan Kosong & 1 & 2 & 5 \\
\hline $\begin{array}{c}\text { Jumlah Penyandang } \\
\text { Disabilitas }\end{array}$ & $1 / 2$ & 1 & 3 \\
\hline $\begin{array}{c}\text { Jumlah Tenaga } \\
\text { Medis Puskesmas } \\
\text { (Perawat) }\end{array}$ & $1 / 5$ & $1 / 3$ & 1 \\
\hline
\end{tabular}

\section{Membuat Matriks Nilai Kriteria}

Hasil pengkonversian dari Tabel 4.1sehingga mendapatkan angka desimal pada setiap kolom. Lalu, kolom jumlah didapat dengan cara menjumlahkan setiap baris masing-masing kolom. Misal, jumlah kolom pada kolom luas lahan kosong didapat dengan cara menjumlahkan setiap nilai baris kolom luas lahan kosong dengan cara:

$$
\begin{aligned}
\sum_{i}^{3} i 1 & =x_{11}+x_{21}+x_{31} \\
& =1,00+0,50+0,20=1,70
\end{aligned}
$$

Hasil penjumlahan setiap baris dapat dilihat pada tabel berikut:

Tabel 3.1 Perbandingan Matriks

\begin{tabular}{|c|c|c|c|}
\hline & Luas Lahan Kosong & $\begin{array}{c}\text { Jumlah Penyandang } \\
\text { Disabilitas }\end{array}$ & $\begin{array}{c}\text { Jumlah Tenaga } \\
\text { Medis Puskesmas } \\
\text { (Perawat) }\end{array}$ \\
\hline Luas Lahan Kosong & 1,00 & 2,00 & 5,00 \\
\hline $\begin{array}{c}\text { Jumlah Penyandang } \\
\text { Disabilitas }\end{array}$ & 0,50 & 1,00 & 3,00 \\
\hline $\begin{array}{c}\text { Jumlah Tenaga } \\
\text { Medis Puskesmas } \\
\text { (Perawat) }\end{array}$ & 0,20 & 0,33 & 1,00 \\
\hline Jumlah & $\mathbf{1 , 7 0}$ & $\mathbf{3 , 3 3}$ & $\mathbf{9 , 0 0}$ \\
\hline
\end{tabular}

3. Membuat Matriks Nilai Kriteria

Nilai pada luas lahan kosong dan kolom luas lahan kosong pada tabel 3 . diperoleh dengan membagi nilai baris kolom luas lahan kosong dengan jumlah kolom luas lahan kosong pada tabel 3.2 dengan cara:

$\sum_{i}^{3} i 1=\frac{x_{11}}{\sum_{i}^{3} i 1}+\frac{x_{21}}{\sum_{i}^{3} i 1}+\frac{x_{31}}{\sum_{i}^{3} i 1}$

$=\frac{1,00}{1,70}+\frac{0,50}{1,70}+\frac{0,20}{1,70}$

$=0,59+0,29+0,12=1,00$
Lakukan perhitungan yang sama pada nilai pada kolom berikutnya sehingga mendapatkan nilai seperti pada tabel berikut:

Tabel 3.2 Matriks Nilai Kriteria

\begin{tabular}{|c|c|c|c|}
\hline & Luas Lahan Kosong & $\begin{array}{c}\text { Jumlah Penyandang } \\
\text { Disabilitas }\end{array}$ & $\begin{array}{c}\text { Jumlah Tenaga } \\
\text { Medis Puskesmas } \\
\text { (Perawat) }\end{array}$ \\
\hline Luas Lahan Kosong & 0,59 & 0,60 & 0,56 \\
\hline $\begin{array}{c}\text { Jumlah Penyandang } \\
\text { Disabilitas }\end{array}$ & 0,29 & 0,30 & 0,33 \\
\hline $\begin{array}{c}\text { Jumlah Tenaga } \\
\text { Medis Puskesmas } \\
\text { (Perawat) }\end{array}$ & 0,12 & 0,10 & 0,11 \\
\hline $\begin{array}{c}\text { Jumlah } \\
\text { Normalisasi }\end{array}$ & 1,00 & 1,00 & 1,00 \\
\hline
\end{tabular}

\section{Hasil Perkalian Matriks Perbandingan}

Hasil perkalian matriks perbandingan berpasangan dengan bobot prioritas juga dapat dilakukan perhitungan dengan cara sebagai berikut:

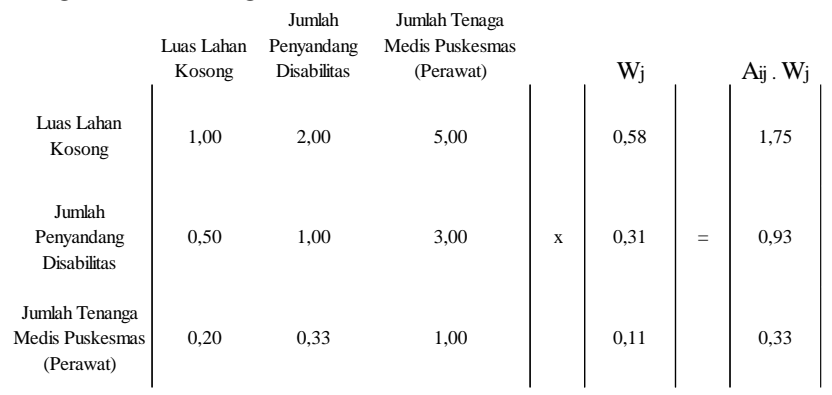

Dengan $\mathrm{W}_{\mathrm{j}}$ adalah bobot prioritas dan $\mathrm{A}_{\mathrm{ij}}$ adalah matriks perbandingan kriteria.

Tabel 3.5 Perkalian Matriks Perbandingan Dengan Bobot Kriteria

\begin{tabular}{|c|c|c|c|c|}
\hline & Luas Lahan Kosong & $\begin{array}{c}\text { Jumlah Penyandang } \\
\text { Disabilitas }\end{array}$ & $\begin{array}{c}\text { Jumlah Tenaga } \\
\text { Medis Puskesmas } \\
\text { (Perawat) }\end{array}$ & Jumlah \\
\hline Luas Lahan Kosong & 0,58 & 0,62 & 0,55 & 1,75 \\
\hline $\begin{array}{c}\text { Jumlah Penyandang } \\
\text { Disabilitas }\end{array}$ & 0,29 & 0,31 & 0,33 & 0,93 \\
\hline $\begin{array}{c}\text { Jumlah Tenaga } \\
\text { Medis Puskesmas } \\
\text { (Perawat) }\end{array}$ & 0,12 & 0,10 & 0,11 & 0,33 \\
\hline
\end{tabular}

Pada tabel 3.5 adalah hasil dari perkalian matriks antara matriks perbandingan berpasangan pada tabel 3.4 dan bobot prioritas kriteria. Nilai kolom jumlah diperoleh dari hasil penjumlahan dari masing-masing kolom.

\section{Hasil Hitungan Matriks Akhir}




\section{Jurnal Sains Komputer dan Teknologi Informasi $\mid$ Page e - issn : 2655-7460. Volume 3 No.1, November 202060 - 69}

Pada data dibawah dapat diberikanlah contoh alternatif pilihan pada penentuan titik lokasi baru pelayanan disabilitas yaitu alternatif Puskesmas A, Puskesmas B dan Puskesmas C yang memiliki kriteria pada tabel berikut:

Tabel 3.6Matriks Hasil

\begin{tabular}{|c|c|c|}
\hline Luas Lahan Kosong & Jumlah Penyandang Disabilitas & $\begin{array}{c}\text { Jumlah Tenaga Medis } \\
\text { Puskesmas (Perawat) }\end{array}$ \\
\hline 0,58 & 0,31 & 0,11 \\
\hline Sub 1 & Sub 1 & Sub 1 \\
\hline Luas & Tinggi & Banyak \\
\hline 1.00 & 1.00 & 1.00 \\
\hline Sub 2 & Sub 2 & Sub 2 \\
\hline Sedang & Sedang & Mencukupi \\
\hline 0.55 & 0.55 & 0.55 \\
\hline Sub 3 & Sub 3 & Sub 3 \\
\hline Sempit & Rendah & Sedikit \\
\hline 0.33 & 0.33 & 0.33 \\
\hline
\end{tabular}

Pada tabel diatas adalah gabungan dari semua nilai prioritas dari masing-masing kriteria dan sub kriteria yang nantinya akan digunakan dalam pemberian nilai alternative untuk perhitungan sistem.

Tabel 3.7 Nilai 3 Puskesmas Alternatif Penentuan Titik Lokasi Baru Pelayanan Disabilitas

\begin{tabular}{|c|c|c|c|}
\hline & Luas Lahan Kosong & $\begin{array}{c}\text { Jumlah Penyandang } \\
\text { Disabilitas di }\end{array}$ & $\begin{array}{c}\text { Jumlah Tenaga } \\
\text { Medis }\end{array}$ \\
\hline PUSKESMAS A & LUAS & SEDANG & MENCUKUPI \\
\hline PUSKESMAS B & SEDANG & TINGGI & SEDIKIT \\
\hline PUSKESMAS C & SEDANG & RENDAH & MENCUKUPI \\
\hline
\end{tabular}

Pada data tabel 3.8 nilai dari tabel 3.7 dikonversikan sesuai dengan matriks hasil pada tabel 3.6. Nilai total lah yang akan menjadi dasar untuk menentukan kriteria alternatif mana yang akan dipilih. Maka, di urutan pertama yang menjadi prioritas pembangunan pelayanan disabilitas baru ialah Puskesmas A yang kedua adalah Puskesmas B dan yang paling akhir adalah Puskesmas C.

Tabel 3.8 Nilai Akhir

\begin{tabular}{|c|c|c|c|c|}
\hline & Luas Lahan Kosong & $\begin{array}{c}\text { Jumlah Penyandang } \\
\text { Disabilitas di } \\
\text { Kelurahan Tersebut }\end{array}$ & $\begin{array}{c}\text { Jumlah Tenga } \\
\text { Medis }\end{array}$ & Total \\
\hline PUSKESMAS A & 1,00 & 0,55 & 0,55 & 2,10 \\
\hline PUSKESMAS B & 0,55 & 1,00 & 0,33 & 1,88 \\
\hline PUSKESMAS C & 0,55 & 0,33 & 0,55 & 1,43 \\
\hline
\end{tabular}

\section{IMPLEMENTASI DAN PENGUJIAN}

\subsection{Implementasi}

Adapun dalam pembuatan sistem informasi geografis penentuan titik lokasi baru pelayanan disabilitas di Kota Banjarmasin merupakan sebuah aplikasi/program yang berbasis website dengan Bahasa pemrograman HTML dan PHP. Sedangkan Konsep kerja PHP sendiri prinsipnya serupa dengan kode HTML. Hanya saja berkas yang diminta didapatkan oleh web server, isinya segera dikirimkan kemesin PHP dan mesin inilah yang memproses dan memberikan hasilnya (berupa kode HTML) ke web server. Selanjutnya web server menyampaikan ke klien. Script PHP berkedudukan sebagai tag dalam bahasa HTML. Bahasa pemrograman ini memiliki fitur struk control, operator, tipe variable, deklarasi fungsi, deklarasi class/object. Untuk manajeman database pada sistem, digunakan MySQL yang dimana MySQL MySQL adalah sistem manajemen database relasional open source (RDBMS) dengan clientserver model. Sedangkan RDBMS merupakan software untuk membuat dan mengelola database berdasarkan pada model relasional. Dibantu dengan Aplikasi Sublime Text yang dimana Sublime Text adalah editor teks untuk berbagai bahasa pemograman termasuk pemograman PHP. berikut dibawah ini adalah tampilan hasil website yang telah dirancang.

\subsection{Halaman Utama}

Pada halaman utama berisi tampilan awal pada saat sudah melakukan login, pengguna langsung ditujukan ke menu utama yang berisi informasi terkait pengembang dan juga terdapat beberapa navigation bar untuk menuju ke halaman lainnya serta informasi data jumlah data yang sudah ada didalam website. 


\section{Johan Wahyudi. Penentuan Titik Lokasi Baru Pelayanan Kesehatan Bagi Penyandang Disabilitas Di Kota Banjarmasin Menggunakan Metode Ahp dan Gis}

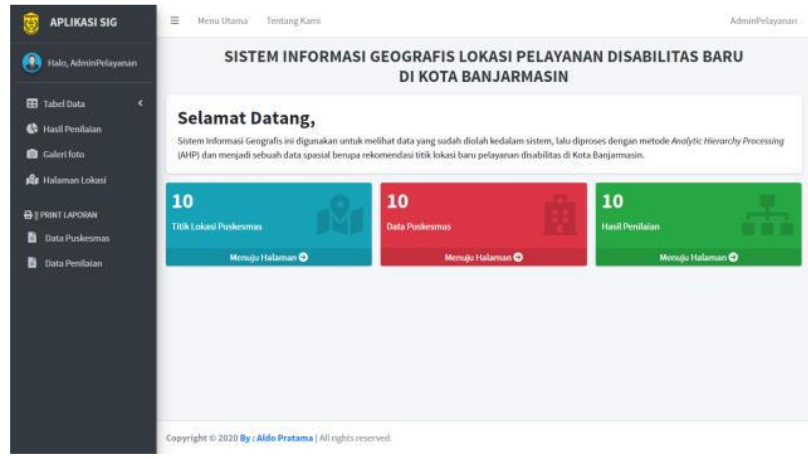

Gambar 4.1 Tampilan Halaman Utama

\subsection{Halaman Lokasi}

Pada halaman ini sistem akan menampilkan info titiktitik lokasi dimana saja tempat pelayanan kesehatan yang tersedia dan juga bisa menampilan detail ataupun menghapus lokasi puskesmas yang sudah disimpan. Pada halaman ini juga disediakan fitur tambah lokasi yang dimana admin bisa menambahkan titik lokasi baru puskesmas terkait.

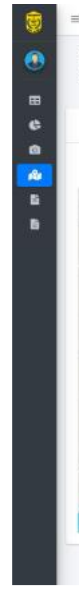

SISTEM INFORMASI GEOGRAFIS LOKASI PELAYANAN DISABILITAS BARU DI KOTA BANJARMASIN

Denah Lokasi Baru Pelayanan Disabilitas di Kota Banjarmasin
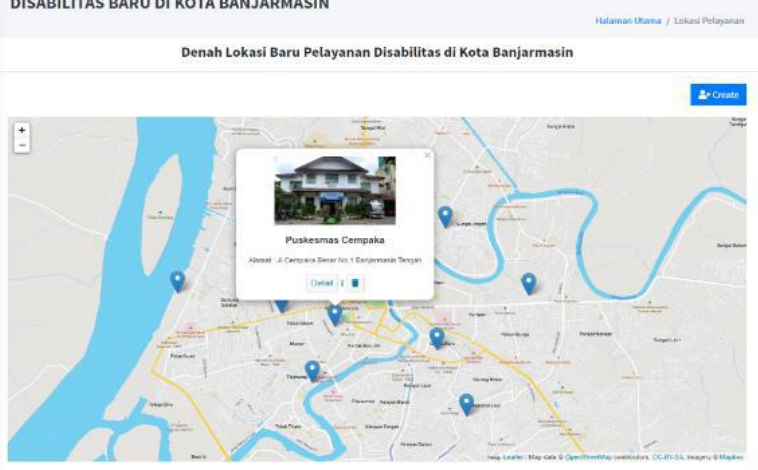

Gambar 4.2 Tampilan Halaman Lokasi

\subsection{Halaman Form Data Penilaian}

Pada halaman form penilaian ini admin melakukan input data penilaian yang dimana disini kita menjadi Langkah awal dari proses metode perhitungan AHP. Pada form ini terdapat beberapa data yang didapat dari kumpulan tabel data yang terhubung menjadi satu. Form ini akan menampilkan data yang dimana admin tinggal memilih dikolom nama puskesmas dan akan muncul fitur modals dari bootstrap 4 yang dimana akan keluar data puskesman mana yang hendak kita nilai dan setelah kita pilih (select), lalu kolom-kolom lainnya akan terisi sesuai dengan nilai yang sudah didapatkan dari data-data terkait.
Kolom-kolom kriteria penilaian yang ada berdasarkan hasil penelitian dari penulis yaitu jumlah penyandang disabilitas yang mengambil nilai dari data pada tabel datakelurahan, serta nilai luas tanah kosong dan jumlah tenaga medis yang didapat pada tabel data puskesmas. Nilai-nilai tersebut merupakan kriteria yang digunakan untuk proses penentuan keterangan. Dimana keterangan di sini merupakan sub kriteria pada berdasarkan pada tabel 6. Pada tabel tersebut terdapat 3 kriteria utama yang dimana setiap kriteria memiliki 3 sub kriteria.

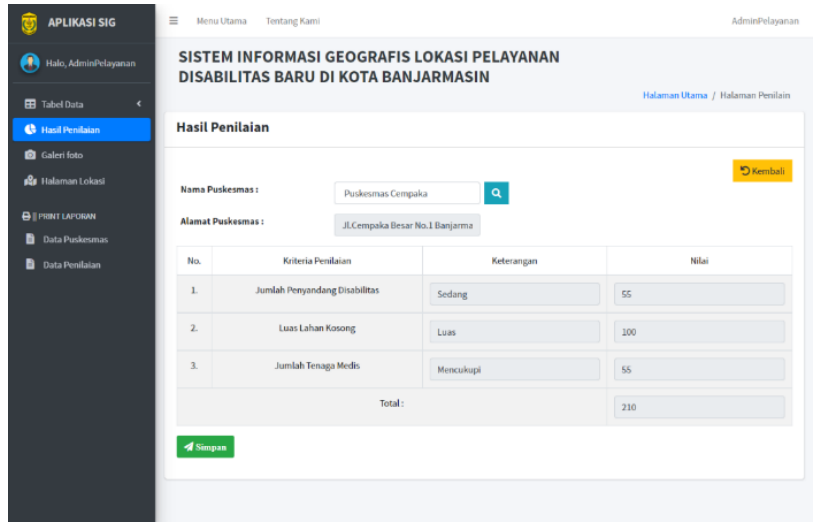

Gambar 4.3 Tampilan Halaman Data Penilaian

\subsection{Laporan Aplikasi}

Pada laporan ini ada beberapa menu pilihan pada laporan yang dicetak. Laporan data puskesmas serta laporan data penilaian.

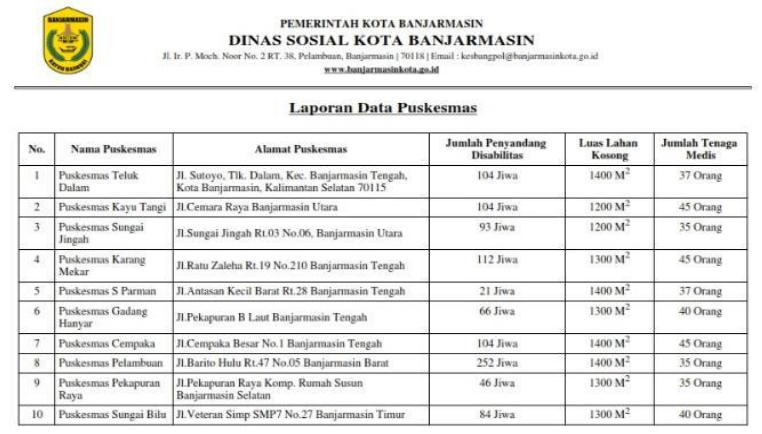

Gambar 4.4Laporan Data Puskesmas 


\section{Jurnal Sains Komputer dan Teknologi Informasi $\mid$ Page e - issn : 2655-7460. Volume 3 No.1, November 2020 60 - 69}

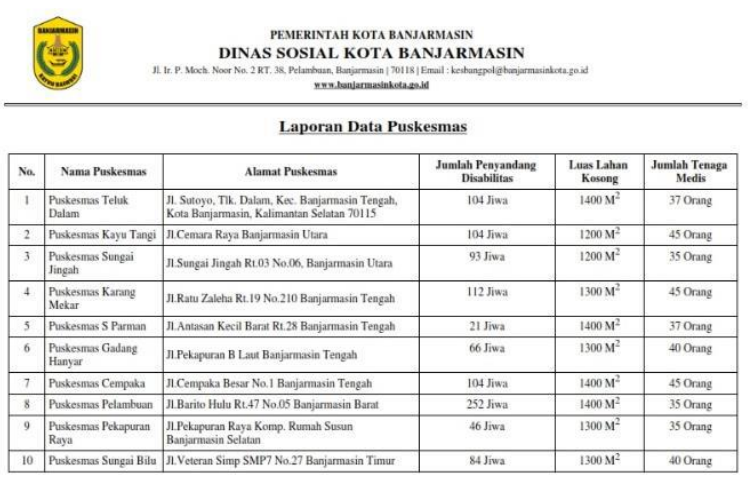

Gambar 4.5 Laporan Data Penilaian

\section{PENUTUP}

\subsection{Kesimpulan}

Dari hasil penelitian dan pembahasan ini, maka dapat diambil beberapa kesimpulan sebagai berikut:

1. Data yang diperoleh dari hasil survei adalah data mengenai seluruh puskesmas yang ada dikota Banjarmasin dan juga informasi mengenai persebaran penyandang disabilitas yang dikelola oleh Pemerintahan Kota Banjarmasin dan juga beberapa komunitas penyandang disabilitas yang ada di Kota Banjarmasin.

2. Website/program ini mengambil data spasial geografis untuk mendapatkan data latitude dan longitude dari sebuah lokasi yang terhubung dengan database MySQL yang digunakan untuk pembuatan denah lokasi puskesmas menggunakan Google Maps.

3. AHP digunakan sebagai metode perhitungan untuk membantu menentukan keputusan pembangunan peyalanan baru untuk penyandang disabilitas di Kota Banjarmasin dengan memperhatikan nilai total yang tertinggi lah yang akan menjadi rekomendasi pembangunan.

4. Dengan adanya website/program ini diharapkan dapat membantu memudahkan pemerintahan Kota Banjarmasin untuk menentukan dan memutuskan lokasi/puskesmas mana yang membuhkan pembangunan pelayanan disabilitas untuk menunjang para penyandang disabilitas agar mendapatkan kesetaran hak dengan warga Kota Banjarmasin lainnya demi menjadikan kota yang inklusif dan dapat diakses untuk semua atau Kota Ramah Disabilitas.

\subsection{Saran}

Saran yang dapat disampaikan antara lain :
1. Penambahan beberapa kriteria pembangunan pelayanan disabilitas baru agar lebih spesifik dalam penentuan rekomendasi pembangunan. Seperti misalnya akses antara penyandang disabilitas dengan puskesmas atau pelayanan terkait dan lain sebagainya.

2. Penambahan fitur pencarian lokasi atau koordinat agar pada saat melakukan Input data lokasi agar lebih spesifik letak geografis dan memudahkan untuk melakukan pengambilan titik lokasi menggunakan makers.

3. Sistem yang berintegrasi langsung dengan sistem informasi Smart City pemerintahan Kota Banjarmasin.

\section{DAFTAR PUSTAKA}

[1]. A.S, Rosa dan M. Shalahuddin. 2011. Modul Pembelajaran Rekayasa Perangkat Lunak. Bandung : Modula.

[2]. Asterina, Nisa, dkk. 2019. Kota Banjarmasin : Sebuah Profil Kota Ramah Disabilitas. United Nations Educational, Scientific and Cultural Organization (UNESCO) : Jakarta.

[3]. Madcoms, 2016. Pemprograman PHP dan MySQL Untuk Pemula :Yogyakarta.

[4]. Ningrium Niken Ratna Wahyu. 2017. Aplikasi Metode AHP Berbasis Spasial Untuk Menentukan Lokasi Reklame di Surabaya. Fakultas Matematika dan Ilmu Pengetahuan Alam Institut Teknologi Sepuluh Nopember Surabaya : Surabaya.

[5]. Nugroho, Adi. 2010. Rekayasa Perangkat Lunak Menggunakan UML \& Java. Yogyakarta : Andi Offset.

[6]. Patel, Jayraj. dkk. 2019. Geographic Information System (GIS) Web-Based Water Pipeline Data Visualization for Decision Support.

[7]. Prahasta, E. 2014. Sistem Informasi Geografis: Konsep-konsep Dasar (Perspektif Geodesi \& Geomatika). Edisi Revisi. Bandung : Informatika.

[8]. Saaty, T. L. (1990). Decision Making The Analytical Hierarchy Process. United States of America : McGraw-Hill. 